\title{
Transgression and transcendence in development of a psychologically safety personality
}

\author{
Irina P. Krasnoschechenko \\ Department of Social and \\ Organizational Psychology \\ K.E. Tsiolkovskiy Kaluga state \\ University \\ Kaluga, Russia \\ kviip@,yandex.ru
}

\author{
Mariam R. Arpentieva \\ Department of Developmental \\ Psychology and Education, \\ K.E. Tsiolkovskiy Kaluga state \\ University, \\ Kaluga, Russia \\ mariam_rav@mail.ru
}

\author{
Irina G. Moiseeva \\ Department of General and Legal \\ Psychology \\ K.E. Tsiolkovskiy Kaluga state \\ University \\ Kaluga, Russia \\ iri25100@yandex.ru
}

\author{
Maria A. Spihenkova, \\ Department of General and Legal \\ Psychology \\ K.E. Tsiolkovskiy Kaluga state \\ University \\ Kaluga, Russia \\ stebbins@yandex.ru
}

\author{
Alexandr V. Kosov \\ Department of Social and \\ Organizational Psychology \\ K.E. Tsiolkovskiy Kaluga state \\ University \\ Kaluga, Russia \\ sanslav@kaluga.net
}

\begin{abstract}
The article examines the socio-cultural conditions of generation and the prohibition of the phenomenon of transgression and its role in the development of a psychologically secure personality. The authors discuss approaches to the phenomenon of transgression in the concepts of spiritual and moral foundations of human existence and development of a psychologically secure personality. The phenomenon of transgression is compared with the phenomenon of transcendence. Transcendence plays an important role in the development of a psychologically secure personality. Transgression manifests itself in desacralization, rejection of values (prescriptions) and violation of cultural prohibitions. Incomplete transgression (not directed its efforts to transcendence, reintegration of man and the world) forms a psychologically unsafe personality. Transgression makes the world more "fractional", patchwork, sometimes not just going beyond borders, but creating these boundaries. It departs from the "monotopy" (unity of the world, time and space, culture and society), to heterotopy. Heterotopia is the space beyond all others, the space in which there are no familiar laws and regulations to the subject. People entering the heterotopia (especially in frontier or border), are forced to adapt to new conditions and somehow the so-called act of transgression, i.e. to overstep the limits of the traditional behavior. It raises epistemological significance of the study of heterotopic transgression. For the individual or group subject of transgressional acts, these acts are one of the typical forms of responding to a meeting with a Stranger / Other. This form gives the individual or the community the opportunity for productive and effective ways of adapting to changing environmental conditions, but also creates the risk of destruction and inefficiency as a personal, and group, both interpersonal and inter-group functioning, development and interaction.
\end{abstract}

Keywords- transgression, the sacred, desacralization, transcendence, product, ban, personality, intercultural interaction, psychologically secure personality

\section{INTRODUCTION}

For the individual or group subject of transgressional acts, these acts are one of the typical forms of responding to a meeting with a Stranger / Other (in new conditions). Transgression give the individual or the community the opportunity for productive and effective ways of adapting to changing environmental conditions and creates the risk of destruction and inefficiency as a personal, and group, both interpersonal and inter-group functioning, development and interaction. Consciousness of the modern secular, devoid of belief in the eternal and common moral and spiritual values of God and society, is characterized by a loss of connection with the intelligible (understandable and existent) world, in the "illusory" dimension of which lived a traditional society.

\section{DISCUSSION}

The gradual weakening of the influence of Christianity and other religions on the life of the society, in a certain sense, contributed not only to his liberation, but also led to a rethinking of the religious concept of "sacred" and perceptions of the mind and feelings, about reality and illusions, etc. [30]. Disappointment in the ideals of the Enlightenment, one of which is the total rationalization of social life, has led many modern philosophers and thinkers to reconsider the view of man himself as homo sapiens and move on to the plural concept of man. The view on the human community also changed: the "age of crowds" marked irrationality as a leading 
feature of intercultural interaction. Desacralization or transgression - one of the phenomena considered in existentialism, accompanies this process of "pluralization." Due to this, the transgression takes on two forms: positive (transcendent, resacralizing) and negative (desacralizing). The "transgression vector" and "transcendence vector" often coincide where the transgression takes the form of resacralization: the search for the other refuses to abandon its own $[20 ; 27]$. And, on the contrary, where desacralization does not end with the acquisition of new values, the transgression remains negative. Transcendence as the realization of the principle of ultimate implies not only reliance on one's own strengths and goals, but also an openness to the influences of Life, God, the emergence of synergies that transform a person who opens his life as a body or person to the life of society or the soul. The transgression can be either more or less orderly, and completely chaotic. The very idea of rejecting value bases violates the "organon principle". Any event of transcendence or breaking the world into itself or itself into the world is subject to strict requirements to the content and process. The conformity of their form and content, which allows us to understand ourselves, preserving the continuity and integrity of the life flow, not only in the state of spiritual doing, psychotherapeutic dialogue, etc., but also in everyday life. With the departure of totalitarianism, the moral crisis did not go away, but only changed its manifestations. The last decades should be considered as its new stage, which is hardly less unsafe than the previous ones: its manifestations are now not so harshly inhuman, but broader, covering not isolated countries but modern civilization as a whole. However, in recent years - the magical era of postmodernism with its total "pluralization" as desacralization, the inhumanity of relations has been intensively growing: from wars and terrorist acts to mass concentration camps and slavery in a variety of forms, starting with slavery in educational, social, health and law enforcement institutions .

In the process of transcendence / transgression, a person chooses between the norms of the world and the norms of God, sacred and everyday. This illustrates the phenomenon of the complex of Jonah, named in the name of the biblical prophet Jonah, who refused to transcend as the realization of his destiny. The book of the prophet Jonah is one of the parts of the Tanakh, the "small prophets" of the Bible. Despite the fact that there is very little room for history and prophecy in the Bible, it is included in the collection of prophetic books of the Bible, since it reveals the fundamental aspects of the notion of the universal meaning of prophecy and the role of the prophet, and also about how a person resists development as salvation. The prophetic and transformative meaning of the Book is indicated in the words of the Savior (Matthew 12:40, Luke 11:32, Bible, 2015): "The Ninevites will rise up to judgment with this generation and condemn it, for they repented of preaching by Ioannina, and, behold, here more than Jonah". "Jesus Christ set the Ninevites as an example of responsiveness to the word of God, showing that God can be granted salvation through repentance to everyone, including all nations. The path of development - one for all - is a moral improvement: the disclosure of this thought is connected with the need to understand that the Messianic Kingdom has a spiritual and universal, rather than a national and "selective" character. As Jonah's example shows, this idea was assimilated with great pain: understanding this aspect - the idea of chosenness - serves as a stumbling block and test-stone for practically all "true" believers. The choice of "truth" as God's grace, the gift of spirituality and "truthfulness"' as ideas about their own "achievements" and significance, or about the fact that God singled out and gave the quality of "sonship" and "significance" only to some - one of the main choices of moral perfection, "And the Lord God planted a plant, and it rose over Ion" (Ion 4: 6). The choice of Jonah is a choice of self-fulfillment or self-destruction, symbolically reflected both in the fate of the tree above it and in the whole history of this prophet. Transgressive movement reflects the phenomenon of betrayal: others and oneself. Jonah betrayed himself, but many, including the biblical prophets, betrayed others. Betrayal - one of the most important in the life of each person, which can be attributed to the category of transcultural and indigenous, initially present (obligate as "inherently inherent" or "resident"), the phenomena of human life. Betrayal is usually called breaking loyalty to someone or not fulfilling a duty to someone (treason, throwing / abandoning children, apostasy as a religious apostasy, etc.). In general, with betrayal as a victim, a person encounters to the extent that he is inclined to "unduly trust" the surrounding people at the expense of relations with God. As a betrayer of treachery, a person encounters when a relationship with God becomes a fiction for him: desacralization seizes new and new spheres of his life. Betrayal is the deliberate infliction of harm (material, moral or physical) to an entrusted person or group of people. One of the most striking betrayals is the betrayal of Judas Iscariot, from that moment the traitors became known as the Judas, in the very betrayal - the "kiss of Juda" as well as the betrayal of Cain, who was angry with his brother because he "loves" more with God. However, the first betrayal, reflecting the "indigenous" nature of the violation, was already committed in paradise: "And the serpent said to the woman: "No, you will not die, but God knows that on the day you eat them your eyes will open, and you will, as gods, who know good and evil" (Genesis 3: 4, 3: 5). Violation of the prohibition, betrayal of God, resulted in death, which one way or another, but constantly binds betrayal and destruction (spiritual, social, and physical). Thus, the (cultural) prohibition, as well as the prescription of something, for example, initiation and service, other forms of transcendence, has an important protective function for the soul. The function of prescribing people to certain norms and rules of behavior, as well as related values, perhaps, is the main thing in the life of society. These norms and rules, fixed in a certain system of prohibitions, become even more effective and the more they subordinate to themselves, the more authoritative their source is. From this, it follows that only their superhuman, Divine origin can give an absolute character to these prescriptions. Therefore, the process of social interaction, impossible 
without building such a system of prohibitions and regulations and following it, assumes (at least in a traditional society) an outlet into the superhuman and supersocial sphere, which will be nothing more than a sphere of the sacred, Divine. The sacral thus makes a connection between external coercion emanating from the social environment into which this individual is included, and by the individual himself, who must internalize those prohibitions and injunctions that this social medium imposes on him. The individual entering into the given society, should not simply obey his will, but also internally agree with it. In other words, he must accept the values on the basis of which these prohibitions and regulations are built. Only with the consent of the majority of the members of the society in the adoption of these values can society function as such, if the values of the superhuman level are abandoned, society is destroyed [30]. One of the stages of destruction is the marginal personality. "... Marginalis (marginalis - located on the edge) is an intermediate state" between", when a person feels deep discomfort and dissatisfaction, because he loses the purpose and meaning of his existence. "He sailed from one shore, but did not yet come to another" [26, p.288]. There are many such people in the modern world. O.V. Ivanovskaya $[7$, p. 2] writes that "from the principle of total collectivism and impersonality, the pendulum of social relations has swung today towards the utmost egocentrism and devaluation of social and cultural values ... the "golden mean" of the pendulum is between herdness, standardity, the desire to be exactly the same just like everyone on the one hand, and extreme individualism, hyper-egocentrism ...". Marginal lives in the world of heterotopy and heterochrony, which is the essence of postmodernity with its patchwork and simulated realities. In this context, "transgression is a gesture that is drawn to the limit" [25, p. 117], "overcoming the irresistible limit", "experience is the limit" [5, p. 67], "the edge of the possible", "burning experience", which "does not attach importance to the boundaries established from without" [2; 19, p. 36].

Transcendence plays an important role in the development of a psychologically secure personality. Transgression manifests itself in desacralization, rejection of values (prescriptions) and violation of cultural prohibitions. Incomplete transgression (not directed its efforts to transcendence, reintegration of man and the world) forms a psychologically insecure personality. Transgression makes the world more "fractional", patchwork, sometimes not just going beyond borders, but creating these boundaries. It departs from the "monotopy" (unity of the world, time and space, culture and society), to heterotopy. Heterotopy, according to $\mathrm{M}$. Foucault, is space after of all others; the legal and moral laws that are customary for society and the individual do not operate, therefore, falling into the heterotopy (especially the frontier one, located on the border of the developed and undeveloped). Heterotopy is forced to adapt to conditions that are incomprehensible to him and, in one way or another, to perform "an act of transgression", to transcend the limits of traditional norms and behaviors that are habitual for him and his environment-the implementation of these norms. In this case, acts of transgression are one of the typical forms of responding to a meeting with a Stranger / Other in new conditions for a transgression subject, which gives the individual or the community the possibility of productive and effective ways of adapting to changing environmental conditions, but also creates the risk of destruction and inefficiency [31, p. 219]. Thus, "transgression itself is not a positive or negative phenomenon. This is one of the mechanisms of adaptation to new conditions of existence that allow a person or society to survive in difficult conditions of heterochrony or heterotopy" [31, p. 228]. "Without feeding on protest, repulsion, he must learn to live in peace, that is, to find peace, to find his place in the world, to find silence and harmony in which a human being can be realized" $[1,4$, p. 15 ; $21 ; 22]$.

P.V. Leushkin notes that "Autotorativity and transgressiveness are singled out as key characteristics of social reality, this is the way to represent social reality, as intersubjective, self-referential and autopoietic. This means that everyday reality has a natural and self-organizing character, and the conditions for its existence are rooted in the very life of a person. "[14, p. 98]. However, in different epochs and in different countries, the "scatter of reality" within reality, the measure of patchiness and the territory of cultural-semantic and moral-ideological "frontiers" as zones between the world that has been mastered and not mastered by man, are different $[12 ; 13]$. There are wandering or "flickering" borders and concepts describing them concepts and metaphors. "The word, in the words of P. Klossowski, became" the grasp of the flight of existence" [10, p. 84], and there is a wandering word in our understanding" 24, p. 99], which creates sparkling and explosive texts that are "a means of freeing the human mind". Consciousness here is freed from the power of trajectories of sense formation given by these or other discourses, it is possible to shift and move prospects. "According to A. Schütz, the semantic gradient of any intention consists of a theme - a field of relevance, a schema of a set of available knowledge and a horizon - an area of accessible typification" [33, p. 26]. In place of rationalism and monolithism comes mysticism and a multiplicity of semantic flaps - realities, some of which are simulacra, some are the designations of the Other, another part is Nothing. As J. Baudelaire pointed out, based on the ideas of J. De Maistre, mysticism appears as a field between the two poles of a magnet: "Only by reaching the deepest abyss of fall, imagination, by contrast, ignites the light of the highest ideals ... as the more brighter the light, the sharper the shadow" [18, p. 160]. "Transgression, in turn, is a form of self-awareness that moves toward self-loss. More precisely, there are no sides ... There is no strict direction in such a movement, but there is a shore - a limit ... It's not just a way of thinking, it's a way of living a thought that, trying to catch itself in the totality movement, improbably aims to get ahead of itself in selfmovement to the absolute, in order to observe one's own death" [21, p. 28].

G. Bataille moves in a peculiar way in the space of this discourse: "I defined the" I "as a value, but I refused to 
confuse it with a deep existence" [21, p. 34, 226]. .. he lives this thought to the extreme extreme". "Systematic coercion of oneself to feel their disgust" [21, c. 36] - so J.-P. Sartre called this experience "cruel disgust" in relation to his own existence. It is connected with the fact that a person desires something that he cannot but desire, but what is not and cannot be confirmed - "the passion that commands such games and terrible dreams is not just a frenzied desire to be "I", this desire to be Nothing" [11;21, c. 228]. Generally speaking, "a transgression violates the limits, but does not return to the familiar world, it opens the way to the unknown. "Any breakthrough in the knowledge of something, in the disclosure of secrecy, is always connected with going beyond borders, with overcoming the ban" [6, p. 12]. Therefore, any discovery ... is a transgression, because it is a way out of the known, understandable. "Most often the result of innovation is not approved ... But time is passing, and what was unacceptable becomes a new norm" [9, p. 97]. However, "the crime of the limit is not its absence" [9, p. 96,3, p. 420;8]. And, therefore, the key moment here is the fact that as a result of a transgressive violation of the law, the social world does not collapse. It continues to exist, since after a point-specific, concrete act of transgression, a person returns in a stable world of legality that can not be shaken by a single violation of the law", at least completely and immediately, for all. There are two opposite ways of reading reality: hermeneutics and transgression. The first path involves an interpretation that reduces heterogeneous storylines to a single semantic and story center, a narrative, to comprehend the unity and continuity of life. The second way involves rejecting possible interpretations and affirming the openness, plurality and transgressiveness of life and its situations, its paradoxicality and complexity. "The transformation of events, situations of everyday factor in the" not casual "extreme situation highlights the fundamental phenomenon of personal meaning, without which it is impossible to adequately define the phenomenon of psychological stress, extreme, injury and loss", - as says M. Magomed-Eminov [32, p .26]. He also notes that "in addition to negative-pained face, which is the main interest of psychologists, Extreme has another downside - produces steadfastness, courage, heroism, compassion, help, illumination, growth, development, transgression, and others" $[16, p .28]$. At the same time,"extremality is defined in formal terms as a function of interaction between the individual and the environment through activity within the context of meaning" $[16, p .30]$. This concept allows "to distinguish in extremeness as a form of non-routine two ... modus - tragic extremality (negative) and transgressive, eudemonic (positive) extremality... tragic extremality, transgressive extremity and everyday life should be considered as an integral constellation of the being of the person .... tragic, dramatic, extreme experiences and transgressive experiences of the transition limit are two sides of extremality, which itself as a mode of being a person is constellated with the everyday mode of being" [16, p. 31]. "In an extreme situation, the triadic structure" disorder - adaptation - growth "arises (or is a condition for the emergence), or in a somewhat different perspective - "suffering - resistance - transgression" [16, p.34]. "In terms of adaptation and development, this triad acquires the following forms": disadaptation - adaptation development. " Phenomenon traumatic (wider - extreme) growth (including, posttraumatic growth), as well as traumatic adaptation resistance is not strictly reductive work [16, p.36], and appears as a transcendental, transgressive work ... victim martyr, character - courage to withstand the tests mudrets- one who has attained enlightenment, illumination, faced with the tragic form the three persons of the person in extreme "[16, s.36-37] in this case, emergency frequent phenomenon - a doubling of the individual, in which" a person ... etc. it is ... on the everyday and not everyday, ordinary and extreme, transordinary self-identity. Contradictions between these identities, including those of a value-semantic nature [15, p. 112-121], in the incidental and post-instinctual situations themselves create both "parasitic" identity structures and the structures of retention (delay) of transgression and personality growth. Three self-identity: self-identity of the victim, the surviving self-identity and self-identity development linked zaimno creating postsobytiynuyu problematic human being in the world (in the suffering, in the stability and growth) "[16, c.34].

With the departure of totalitarianism, the widespread dissemination of practices and attitudes of transgression, "transgressing" all and all norms, has become a new form of self-destruction of communities [28]. Psychedelic revolution in the West, and in some measure, and in Russia, ethical nihilism, is highly characteristic of the youth subcultures, to the avant-garde, and then the latest transavangard art . There is atmosphere of total permissiveness, dominance of hedonism and consumerism in a mass culture, severe spiritual and moral degradation and the ethical decline and ethical vacuum that arose after the collapse of socialism in the countries of the former USSR and other socialist countries. This atmosphere have placed the communities and cultures of our country on the brink of moral acceptance behavioral and criminal environmental standards. Well-known criminals, without giving up all criminal values and styles, became publicly famous and influential members of society. "Prison law" implicitly replaced at the turn of the centuries the laws of social and claim to offset the divine laws.

\section{RESULtS}

In the life of every person, every ethnos and his culture, there is a struggle to decrease or increase: from the worm to God, from oneself to another, etc., from culture to lack of culture and cultural "universals". This is especially evident in the religious and spiritual practices of peoples: harmonization and acceptance in the religious sphere means that people and people have managed not only to find a common language, but have also grown to a level of transcendence. When we speaking about the results of spiritual practices and their significance for the development of society, it is necessary to remember the fruits of the Spirit in the interpretation of the apostle Paul:"But the fruit of the Spirit is love, joy, peace, longsuffering, gentleness, goodness, faithfulness, gentleness, self-control. On such there is no law "(Galatians 5: 22-23) 
[28]. S.S. Khoruzhiy, analyzing the formation of the "posthuman", notes the need to create synergistic hermeneutics or hermeneutics of posthuman trends ("vectors"), which will allow us to comprehend the anthropological aspects of the transformation of humankind. This transformation including in the process of its "drawing" into the technogenic world, to understand the way in which it is constituted Man, the role of dialogue and face-to-face meetings [28]. Psychotherapy and other spiritual practices help to understand and master this method and also to assess the danger of the modern anthropological situation consisting in the active and versatile game of mankind "downgrade" (self), the transgression and the break of human, brotherly or friendly relations (love relations), their replacement of consumption (power and use). O.A. Sedakova notes the role of friendship between people and peoples: a person as a transcendent being does not coincide with his "cash" and does not fully comprehend the internal, essential task of when, how and why to get out of it, saving "cash itself, and opening it up to meet with the other [20, p.65-66,79]. Only free people who are capable of "undefended", parity and mature relationships, based on non-mythic life goals (love), can be friends. The gift of friendship is that the other gives the person his most more one who gives. According to O. Sedakova, friendship should not be confused with relations built in the image of "blood" ties - a "blood" brotherhood that prescribes love as a component of social ties in the family, or with utilitarian or forced unions that have an external goal or are created by certain external circumstances (based on fictitious life goals). A friend gives a friend a return to himself, to his essence, his theion, and as a gift, he waits for the same - his theion [20, p.41]. Another aspect of moral relations, including as a result of spiritual practices, is freedom: where there is no morality, there is no friendship and freedom to be friends, cohesion arises as a variant of violent synergy (S.S. Horuzhiy's term), "connectedness by one chain". "In" cohesion "there is no personal attention to each other and participation, respect, there is no free and voluntary unity with others - free $[29, \mathrm{p}$. 782 - 783]. Spiritual practice at the same time combines austerity and austerity of the soul, helps awareness as I understand the reality - the waking and sobering of a person in the face of threats of desacralization and negative transgression. Modernity makes it possible to search for and create many practices that create / comprehend the human in a person, create an interpersonal space dialogue. At the same time, the main problem today is the domination of imitations and simulacra, desacralization and "detranscendentalization". At the same time, since the beginning of time, "people have learned to carry not only physical but also metaphysical stress, and above all concern" about "valued values", "... all that today people throw themselves off in pursuit of their own comfort" [28, p.709]. Imitations arise there, "where metaphysical phenomena are understood objectively, reify: where" eternal values "are" nothing more than a thing that can be repeated ... where consciousness refuses to take risks "- the risk of change and understanding, the risk of meeting and loving, the risk of uncertainty and choice, etc. [28, p.709].
In the discourse-analytic approach of E. Laclau and S. Mouff, the situation of resolving the antagonism between discourses by establishing the dominance of one of them is defined as the establishment of hegemony [34; p. 134-145]. "Not only does the boundary between the sacred and the profane environment reappear, turning the sedentary belonging of the faithful into nomadic estrangement, but the rhetorical strategy of tolerance and acclimation the sacred appropriated by the profane is substituted, at least from the point of view of the ... community as dynamic subject, by an opposite rhetoric strategy of invasion and exile the sacred... The simulacrum of transcendence, which was transported outside the temple in order to sacralize its surroundings, is profaned by them, lost in an alien environment" [35, p. 346]. Religious and other sacral "'rituals become playful routines, through both a reemergence of the idea of meaning as alternative and a despiritualization of the flesh that... dispels the sacredness of rituals and their symbolic efficacy. The placement of the simulacrum of transcendence reveals the nonemendable character of the boundary that separates it from immanence" [35, p. 346]. Simulating personality is a danger for themselves and for others. The loss of the significance of life and the transformation of life into a playful routine lead a person to the brink of self-destruction. However, since the person "is afraid" of himself more and more longly, he is the first to destroy the people around him. This is the mechanism of everyday terrorism, which grew from philistinism and did not grow to a conscious protest against everyday, routine violence. Instead, a terrorist and another subject, unsafe to himself and the world, destroys the concept of violence and its borders [36; 37; 38]. Scientists and scholars tend to distinguish relational transgressions into three approaches. The first approach focuses on the aspect of certain behaviors as a violation of common and transordinaly relational norms and rules. The second approach focuses on the understand consequences of different types of behaviors, particularly the degree to which they hurt the victim, imply disregard for the victim, and imply disregard for the relationship. The third and final approach focuses more specifically on behaviors that constitute infidelity (a common form of relational transgression) [38]. Transgression replaces the removal (Aufhebung), essential (and not simply not simply a qualitative) jump in transcendence. In this case, researchers focus attention to the fact that the transgression, as well as the removal, transgresses limit, but this act does not succeed, and there is just one more mutation within the initial state of the culture / situation. They also note the spontaneous nature of transgressions. The transgressive subject at the time of the transgression does not set himself the task of overcoming the limits of his society, his culture. He also does not seek to stay in them.

\section{CONCLUSION}

The phenomenon of transgression is compared with the phenomenon of transcendence. Transcendence plays an important role in the development of a psychologically secure personality. Transgression manifests itself in desacralization, rejection of values (prescriptions) and violation of cultural 
prohibitions. Incomplete transgression (not directed its efforts to transcendence, reintegration of man and the world) forms a psychologically unsafe personality. Transgression makes the world more "fractional", patchwork, sometimes not just going beyond borders, but creating these boundaries. It departs from the "monotopy" (unity of the world, time and space, culture and society), to heterotopy. The replacement of transcendence with transgression forms the main mechanism of everyday terrorism. It reveals the mechanism of formation, or rather the deformation of a person who has not managed to overcome the alienation and consumerism of philistinism, to grow up to an expanded and conscious protest against everyday, routine violence. This person has not acquired the competences that make up the culture of violence. Instead, a terrorist and another subject, unsafe to himself and the world, destroys the concept of violence and its borders. On this path, he destroys the surrounding world, loses the value of rituals, people, being. The culture of violence is the knowledge and ability to distinguish the necessary violence-coercion as protection from danger and violence-the pleasure of human suffering and the destruction of the world. A safe person is safe primarily because it has such competencies, which make up their knowledge and skills.

\section{REFERENCES}

[1] O.D. Agapov, "Strategies of transcendence and transgression in the social and philosophical dimension", in Socio-philosophical essays: KazanEkaterinburg collection of scientific articles. Ed. O.D. Agapov. Kazan: Kazan State Universiuty, 2014, pp. 4-18. (In Russian)

[2] G. Bataille, "Prohibition and transgression", 2017. URL: http://vispir.narod.ru/bataj2.htm (accessed 10.10.2017) (In Russian)

[3] G. Bataille, "Sovereignty", in Bataille G. Damn part: sacred sociology, 2006. Moscow: Ladomir, 742p. (In Russian)

[4] V. V. Bibikhin, "Internal form of the word". St. Petersburg: Science, 2008, 420. (In Russian)

[5] M. Blansho, "Experience-limit", in Tanatografiya Eros: Georges Bataille and French thought of the middle of XX century. St. Petersburg: Mithral, 1994, 346. (In Russian)

[6] V.A. Zimin, "The function of transgression", in Psychoanalysis and art. Comp. EA Spirkina. Moscow: Kogito-Center, 2011, pp. 11-35 (In Russian)

[7] O.V. Ivanovskaya , "Transcendence against transgression", in Scientific problems of humanitarian research, 2010, vol. 1, pp. 256-268. (In Russian)

[8] N.A. Isaev, "Crime as an act of transgression", in Society and man, 2013, vol. 3-4 (6), pp. 75-77. (In Russian)

[9] S.M. Kashtanova, "Transgression of social and cultural transgression. Historical, philosophical, political and legal sciences, culturology and art history", in Questions of theory and practice, 2014, vol. 11-2 (49), pp. 95-97. (In Russian)

[10] P. Klossovski, "Simuljakr Georges Bataille", in Tanatography of Eros: G. Bataille and French thought of the twentieth century. St. Petersburg Mithral, 1994, pp. 79-91. (In Russian)

[11] I.N. Kruglova, "“Internal and external": a game of transgression", in Bulletin of Tomsk State University, 2008, vol. 309, pp. 27-31. (In Russian)

[12] D.V. Kulikov (2013) "Phenomenology of the transgression of ordinary consciousness", in Personality. Culture. Society, XV, vol. 1 (77), pp. 112-116. (In Russian)

[13] N.V. Lafitskaya, "Transgression", in Professional psychotherapeutic newspaper, 2013, vol. 2, pp. 5-6. (In Russian)

[14] R.V. Leushkin, "Modes of constructing social reality: autonarration and transgression", in Philosophical thought, 2015, vol. 11,pp. 98-111. (In Russian)

[15] M.Sh. Magomed-Eminov, "Psychology of the survivor. Bulletin of the Moscow University. Ser. 14, Psychology”, 2005, vol. 3, pp. 112-121. (In Russian)
[16] M.Sh. Magomed-Eminov, "Phenomenon of Extremality. Bulletin of St. Petersburg University. Series 12. Psychology. Sociology. Pedagogy”, 2010, vol. 1, pp. 28-38. (In Russian)

[17] Markov B.V. (2011) People and signs: the anthropology of interpersonal communication. St. Petersburg: Science, 522p. (In Russian)

[18] Nolman M.L. (1979) Baudelaire. Fate. Aesthetics. Style. Moscow: Hood. lit., 316p. (In Russian)

[19] LG. Pugacheva, "The Border Phenomenon as the Basis of Intentionality of Reason and Objective Perception of Reality", in Izvestiya Saratovskogo Universiteta. Ser. Philosophy. Psychology. Pedagogy, 2009, vol. 2,pp. 36-41. (In Russian)

[20] O.A. Sedakova "Moralia. Volume IV. Moscow: Russian Foundation for the Promotion of Education and Science", 2010, 505p. (In Russian)

[21] G. Bataille, "Tanatography of Eros: G. Bataille and French thought of the XX century”. St. Petersburg: Mithral, 1994, 346p. (In Russian)

[22] M.S. Topchiev (2015) Religious transgression and its influence on modern society. Historical, philosophical, political and legal sciences, culturology and art history. Questions of theory and practice, vol. 11-3 (61), pp. 153-157. (In Russian)

[23] M.S.Topchiev, V.S. Dryagalov, "Features of religious transgression on the frontier", in The Caspian region: politics, economy, culture, 2015, vol. 4 (45), pp. 257-260. (In Russian)

[24] V.T. Faritov, "Problem of philosophical language (transgression and transcendence in philosophical utterance)", in Actual questions of social sciences: sociology, political science, philosophy, history, 2014, vol. 41-42, pp. 94-100. (In Russian)

[25] M. Foucault, "On the transgression", in Tanatography of Eros. Georges Bataille and French thought of the middle of the twentieth century. Comp. S.L. Fokin. St. Petersburg: Mithral, 1994, pp. 110-132. (In Russian)

[26] K.M. Khoruzhenko, "Culturology: the encyclical. Words". Rostov-onDon: Publishing house "Phoenix", 1997, 288p. (In Russian)

[27] S. Horuzhiy, Zona. Almanac "The Swan", 2005, vol. October, 02, pp. 445, URL: http.. www. lebed. com. 2005. art4338. htm (accessed 10.10.2017) (In Russian)

[28] S.S. Horuzhiy, "From synergetic anthropology to social philosophy, or dialogue with Max Weber", in Horuzhiy S.S. New methods in solving fundamental problems of social philosophy: synergistic anthropology. Moscow: Knowledge, 2009, 715p. (In Russian)

[29] S.S. Horuzhiy "Transformative anthropology through the eyes of synergistic anthropology (to the problem of the Post-Man)", in Diogenes' Lantern. The project of synergistic anthropology in the modern humanitarian context. Moscow: Progress - Tradition, 2010, pp. 782 - 783. (In Russian)

[30] N.P. Tsygulya, "The phenomenon of the sacral in "Violence and the Sacred" by René Girard", in Uchenye zapiski Russian State Social University 2010, vol. 2, pp. 96-98. (In Russian)

[31] O.S. Yakushenkova, "Religious transgression under conditions of heterotopy", in Polytematic network electronic scientific journal of the Kuban State Agrarian University, 2015, vol. 113, pp. 219-229. (In Russian)

[32] M. Magomed-Eminov "Post-traumatic stress disorders as a loss of meaning of life"', in Halpern D., Voiskunsky A. (Eds.). States of mind. Oxford, Oxford University, 1997, pp. 238-250.

[33] A.Schutz "Collected papers Vol. I. The problem of social reality". Ed. by M. Natanson. The Hague: Martinus Nijhoff, 1962/1973, 131p.

[34] E. Laclau, C. Mouffe, "Hegemony and Socialist Strategy", in Towards a Radical Democratic Politics, London: Verso, 2001, 198p.

[35] K.G. Valente, "Transgression and Transcendence: as a Response to "A New Philosophy"', in Nineteenth-century contexts, 2004. vol. 26, 1, pp. 61 77. doi: 10.1080/08905490410001683309

[36] M. Leone, "Transcendence and Transgression in Religious Processions" in Signs and Society, 2014, vol. 2(2), pp. 314-349.

[37] V.V. Gusachenko, "Transcendention - transgression transcendention?", in Scientific Notes of Taurida National V.I. Vernadsky University. Series: Philosophy. Culturology. Political sciences. Sociology, 2010vol. 23 (62), 1, pp. 46-49.

S. Metts, \& W. Cupach, "Responses to Relational Transgressions: Hurt, Anger, and Sometimes Forgiveness". In B. Spitzberg \& W. Cupach (Eds.), The Dark Side of Interpersonal Communication. New York: Routledge, 2007, pp. 243-274. 